\title{
DIE VERPLEEGKUNDIGE AS PRESEPTOR IN PERSONEELONTWIKKELING IN OPLEIDINGSHOSPITALE IN NAMIBIË
}

\author{
K. Jooste en C.M. Nel
}

\begin{abstract}
Opsomming
In 'n ondersoek wat in 1991 uitgevoer is word gefokus op die rolverulling van die preseptor in personeelontwikkeling in opleidingshospitale in Namibië. Soos in vele lande word die klimaat van verpleegdienste in Namibië deur voortdurende verandering in die praktyk van die professionele verpleegkundige gekenmerk. Die preseptore moet die professionele verpleegkundige begelei in persoonlike en professionele ontwikkeling.
\end{abstract}

\begin{abstract}
A study undertaken in 1991 focused on the role fulfilment of the preceptor in staff development in training hospitals in Namibia. As in the case in many countries the nursing service climate in Namibia is characterised by constant change in the practice of professional nurses. The preceptormust accompany the professional nurses in their personal and professioanl development.
\end{abstract}

\section{INLEIDING EN ORIËNTERING TOT DIE STUDIE}

Die verpleegkundige in beheer van 'n eenheid vervul 'n opvoedkundige funksie gelykwaardig met haar administratiewe, professionele en navorsingsfunksie.

In die opleidingshospitale van Namibië word die onderrigfunksie van die verpleegkundige in beheer van 'n eenheid sedert 1986 beklemtoon deurdat die rol van preseptor aan hierdie persoon toegeken is. Die benoeming van die verpleegkundige in beheer van 'n eenheid as preseptor, het saamgeval met die instelling van die nuwe geïntegreerde vierjaarkursus. Die preseptor se onderrigfunksie is egter uitgebrei na personeelontwikkeling van alle geregistreerde en ingeskrewe verpleegkundiges in haar eenheid.

Gesien in die lig van verpleegbestuur is personeelontwikkeling vir professionele verpleegkundiges as praktisyns belangrik, veral vir hul voortgesette bekwaamheid en aanpassing tot veranderinge in die verpleegpraktyk. Voortgesette leer en bekwaamheid na afloop van basiese opleiding is essensieël om met die nuutste ontwikkelinge en inligting in verpleegpraktyk en -bestuur tred te hou. Waar die professionele verpleegkundige nie voldoende personeelontwikkelingsgeleenthede gebied word nie kan stagnasie, gebrek aan motivering en gevolglike verlies aan werklus intree.

\section{PROBLEEMSTELLING}

Onsekerheid het bestaan of die preseptore hul personeelontwikkelingsfunksie na wense vervul. Min was bekend oor die persoonlike sieninge van preseptore betreffende hul personeelontwikkelingsfunksie asook hoe professionele verpleegkundiges die preseptorsrol in die praktyk ervaar. Die oorhoofse probleem in hierdie ondersoek was om te bepaal, hoe die preseptore hul rol vervul ten opsigte van die ontwikkeling van professionele verpleegkundiges in Namibië?

\section{DOEL VAN DIE ONDERSOEK}

Die doel van die ondersoek was om die volgende te bepaal:

- Tot watter mate die preseptor se rolvervulling in personeelontwikkeling doeltreffend is;
- Hoe die verpleegkundige as ondergeskikte die rol van die preseptor ervaar.

\section{AANNAMES VAN DIE ONDERSOEK}

Die volgende aannames met betrekking tot die oorhoofse probleem, naamlik hoe die preseptore hul rol vervul in die ontwikkeling van professionele verpleegkundiges, het die grondslag van die ondersoek gevorm:

- preseptore beskik nie oor die essensiële vaardighede vir personeelontwikkeling nie;

- opvoedkundige geleenthede vir personeelontwikkeling vir verpleegkundiges word nie doelgerig beplan nie;

- die preseptore volg nie die korrekte onderrigbenadering vir personeelontwikkeling van verpleegkundiges nie;

- die preseptore evalueer nie die verpleegkundiges se professionele ontwikkeling doeltreffend nie.

\section{LITERATUURSTUDIE}

In die literatuursoeke is gefokus op perspektiewe van die preseptor se insette in personeelontwikkeling. Verskeie outeurs, Douglass (1984:288), Bachman en Ridley (1984:16), Davis (1987:951) en Mooney, Diver en Schnackel (1988:35) het in die literatuur aangedui dat die preseptor se insette in personeelontwikkeling gepaard moet gaan met:

- die gebruik van spesifieke vaardighede;

- die doelgerigte beplanning van opvoedkundige geleenthede;

- die volg van 'n volwasseneonderrigbenadering;

- doeltreffende evaluering. 
Die feit dat daar ooreenstemming by bogenoemde outeurs bestaan oor die belang van bogenoemde aspekte sluit aan by Dodwell en Lathlean (1987:312) wat die omvang en die belang van die preseptor se rol in personeelontwikkeling beklemtoon, om die behoeftes van die ondergeskikte te vervul.

Enkele verskille in die sienings van outeurs het voorgekom, bv.:

- die moontlikheid om meer as een ondergeskikte aan die preseptor toe te wys (Shogan, Prior \& Kolski 1985:140; Walters 1981:246);

- die potensiaal van elke verpleegkundige om 'n effektiewe preseptor te wees (Bachman \& Ridley 1984:16; Davis 1987:951);

- die tydperk en omvang van 'n voorbereidingsprogram vir die preseptor(Goldenberg 1987/88:14; Hart 1989:8; Modic \& Bowman 1989:79).

\section{METODOLOGIE VAN DIE ONDERSOEK}

'n Kwantitatiewe benadering is in hierdie ondersoek gevolg om die rol van die preseptor in opleidingshospitale in Namibië, te beskryf en te interpreteer.

Die ondersoek was kwantitatief van aard aangesien:

- die literatuurstudie 'n essensiële deel van die ondersoek uitgemaak het, wat voor die data-insameling gedoen is;

- verhoudings tussen veranderlikes beskryf was;

- die ontleding van data deur middel van 'n faktorontledingg eskied het, om die korrelasies tussen die onderskeie veranderlikes aan te toon;

- aannames vooraf geformuleer is en deur die navorsingsbevindinge verwerp kon word.

\section{Populasie en steekproef}

Die populasie het bestaan uit alle verpleegkundiges verbonde aan die twee opleidingshospitale in Namibië. Die twee groepe van die populasie wat betrokke was by personeelontwikkeling in opleidingshospitale in Namibië was vir doeleindes van hierdie ondersoek:

- verpleegkundiges wat as preseptore opgetree het $(\mathrm{N}=51)$;
- professionele verpleegkundiges aan wie personeelontwikkeling gebied was $(\mathrm{N}=478)$.

Alle eenhede in die opleidingshospitale waar preseptore aangestel was, is in die ondersoek ingesluit.

Alle preseptore en professionele verpleegkundiges is in die opname ingesluit behalwe vyf van die preseptore en tien van die verpleegkundiges wat aan die voorondersoek deelgeneem het.

Dus het die navorsingspopulasie bestaan uit 46 preseptore en 468 verpleegkundiges (Tabel 1).
Betroubaarheid en geldigheid van die instrumente

Die betroubaarheid van die meetinstrument word deur Polit en Hungler (1987:316) as volg beskryf: "... the degree of consistency with which it measures the attribute it is supposed to be measuring" (Polit \& Hungler 1987:316).

Vir gesigs- en inhoudsgeldigheid het dosente in verpleegadministrasie aan Unisa en die statistikus voor die aanvang van die voorondersoek die vraelyste krities beskou en voorstelle ter verbetering gemaak. Inhoudsgeldigheid is daaraan getoets of die items die doel en

\begin{tabular}{|l|r|r|r|r|}
\hline \multicolumn{5}{|c|}{ Totale terugvoer op uitgestuurde vraelyste } \\
\hline \multicolumn{2}{|c|}{ Respons } & $\begin{array}{c}\text { Aantal } \\
\text { Preseptore }\end{array}$ & $\%$ & \multicolumn{2}{c|}{ Aantal } \\
\hline & 46 & 100,0 & 468 & 100,0 \\
\hline Vraelyste uitgestuur & 36 & 78,3 & 170 & 36,3 \\
\hline Vraelyste ontvang & 4 & 8,7 & 26 & 5,6 \\
\hline Vraelyste onbruikbaar & & & & \\
\hline
\end{tabular}

Ontwikkeling en aard van die navorsingsinstrumente

Twee afsondelike vraelyste vir onderskeidelik die preseptore en verpleegkundiges is ontwikkel. Die twee vraelyste het nie deurlopend ooreenstemmende items bevat nie maar beide was vir beskrywende doeleindes in vyf afdelings ingedeel. Vraelys 1 het 107 veranderlikes en vraelys 2 het 132 veranderlikes bevat.

\section{Voorondersoek}

$\mathrm{Na}$ toestemming van die betrokke owerhede tot die ondersoek verkry is, is 'n voorondersoek onderneem om die uitvoerbaarheid van die ondersoek te toets en soos Reid en Boore (1987:28) dit stel "to try out the study instruments and to test the feasibility of the data collection process".

Vraelyste is aan 'n navorsingsassistent in Namibië gestuur en is per hand aan onderskeidelik vyf preseptore en tien verpleegkundiges van die teikenpopulasie uitgedeel. Die deelnemers van die voorondersoek het alle items beantwoord en geen belangrike meetinstrumentdefekte, soos geen respons op sekere items, is nie geidentifiseer nie. Interpretasieprobleme is slegs in twee items van die vraelyste geïdentifiseer en sodanige items is verbeter. aannames soos gestel vir die ondersoek, voldoende verteenwoordig. Dit is gedoen deur die topbestuur van die verpleegdiens van die Departement van Nasionale Gesondheid en Welsyn en waarnemende dekaan van die Fakulteit Gesondheidswetenskapppe aan die Universiteit van Namibië.

Konstrukgeldigheid van die meetinstrument is bepaal deur die proses van faktorontleding wat na afloop van die opname gebruik is om verskillende items van onderliggende konstrukte (faktore) te identifiseer en saam te groepeer (vraelys 2) (Tabel 2). Die betroubaarheid van die faktorontleding is deur middel van Cronbach se Alfa uitgewys.

\section{METODE VAN DATA-INSAMELING}

Vraelyste is persoonlik na Namibigeneem. Vraelyste is in Windhoek oorhandig aan 'n navorsingsassistent en data-insameling is indringend bespreek. 'n Dosent op Oshakati het vrywillig ingestem om behulpsaam te wees met die uitdeel van vraelyste wat per vliegtuig na haar gestuur is. Vraelyste is weer deur navorsingsassistente ingeneem en per vliegtuig na die navorser teruggestuur.

\section{DATA-ONTLEDING EN AANBIEDING}

Die data is in drie dele aangebied.

Ooreenstemmende vrae van beide vraelyste is ontleed en bespreek deur 
Tabel 2

Ontleding van faktore

\begin{tabular}{|l|l|}
\hline \multicolumn{1}{|c|}{ Konstrukte Meetinstrument } & \multicolumn{1}{c|}{ Faktore } \\
\hline Vaardighede van die preseptor & 1. Agemene vaardighede \\
& 2. Onderrigvaardighede \\
Beplanning van leergeleenthede & 3. Beplanning van leergeleenthede \\
Onderrigbenadering & 4. Algemene leerbeginsels \\
Evaluering & 5. Onderrigbeginsels \\
\hline
\end{tabular}

gebruikmaking van die Chi-kwadraat, om vas te kon stel of die waargenome frekwensies betekenisvol van die verwagte frekwensies afgewyk het.Uit 'n statistiese tabel ( $\mathrm{X}$ - verdeling) is die kritieke X - waardes vir 'n tweekantige toets met 1 graad van vryheid afgelees: $3,84(5 \%$ peil of 0,05$)$ en $6,64(1 \%$ of 0,01 ). Waarneembare verskille is tussen die response van die preseptore en verpleegkundiges waargeneem.

'n Beskrywende ontleding van items van beide vraelyste is gedoen.

'n Tetrachoriese korrelasie is gedoen waar items van vraelys 2 gegroepeer, ontleed en bespreek is. Die tetrachoriese korrelasiekoëffisiente is bereken en was die aanloop tot die faktorontleding. Ten einde die betroubaarheid van die faktorontleding te toets is daar gebruik gemaak van skaaltellings. Cronbach se Alfa het ' $n$ hoë betroubaarheid van die skaaltellings van die geïdentifiseerde ses faktore aangedui.

\section{GEVOLGTREKKINGS VAN DIE ONDERSOEK}

\section{Algemeen}

- Vorige onderrigervaring van die preseptor

Van die dertien $(40,6 \%)$ preseptore wat aangedui het dat hul wel oor onderrigervaring beskik het, het drie $(9,4 \%)$ nie sodanige ervaring gespesifiseer nie. Slegs tien $(31,2 \%)$ preseptore kon hul onderrigervaring spesifiseer en het hulle vorige onderrigervaring toegeskryf aan kliniese onderrig, indiensopleiding en gemeenskapsdiens. Preseptore wat aangedui het dat hulle oor onderrigervaring beskik $(40,6 \%)$ het gemiddeld twee jaar ondervinding in onderrig gehad.

- Aantal verpleegkundiges aan die preseptor toegewys

Daar is gevind dat gemiddeld vier verpleegkundiges aan elke preseptor toegewys word. Dit het geblyk dat die verhouding van verpleegkundiges aan die preseptor toegewys te hoog is, veral waar die preseptor in beheer van 'n eenheid funksioneer en ook 'n onderrigfunksie ten opsigte van ander kategorie- verpleegpersoneel het.

\section{- Professionele kwalifikasies}

Dit was opvallend dat slegs vier $(12,5 \%)$ preseptore oor 'n onderwyskwalifikasie beskik teenoor sewe $(4,9 \%)$ verpleegkundiges wat dié kwalifikasie het, maar nie as preseptore aangestel was nie.

\section{- Akademiese voorbereiding en} privaatstudies

Slegs die helfte $(50 \%)$ van die preseptorgroep was by privaatstudies betrokke. Geen persoon in die studiegroep van preseptore en verpleegkundiges was besig met nagraadse studies nie. Ten tye van die ondersoek het geen preseptor reeds oor 'n B-graad in verpleging beskik nie. Hierteenoor het drie $(2,1 \%)$ verpleegkundiges reeds oor 'n B-graad in verpleging beskik.

\section{- Probleme wat die preseptor met} verpleegkundiges ondervind

Enkele probleme wat preseptore met verpleegkundiges in die werksituasie ondervind is die volgende:

* Die verpleegkundiges toon'n gebrek aan selfvertroue en toon 'n swak selfbeeld.

* Die verpleegkundiges kan nie goeie dissiphne in die eenheid handhaaf nie. * Verpleegkundiges is geneig om nie besluite te neem in die afwesigheid
Persentasie Respondente van die preseptor nie.

* Verpleegkundiges beskik oor geen selfmotivering nie, en moet voortdurend deur die preseptor aangemoedig word.

Essensiële vaardighede van die preseptor vir personeelontwikkeling

- Kommunikasievaardighede

'n Betekenisvolle verskil het bestaan tussen die response van preseptore en dié van verpleegkundiges. 'n Betekenisvolle $28(19,44 \%)$ van die verpleegkundiges teenoor geen $(0 \%)$ preseptore meen dat gedagtes nie met die preseptor gewissel kan word nie. Die preseptor benut dus haar kommunikasievaardighede tot 'n redelike mate in die deel van gedagtes met verpleegkundiges.

\section{- Aanstelling van preseptore}

Die meerderheid van twintig $(62,5 \%)$ van 32 preseptore, het aangedui dat hul nie vanweë hul opvoedkundige kwalifikasies aangestel word nie.Hierteenoor het die meerderheid van $25(78,1 \%)$ preseptore aangedui dat hul spesifiek aangestel is vanweë hul belangstelling in verpleging en hul begrip van interpersoonlike vaardighede. Die respons van preseptore dui daarop dat die waarde van opvoedkundige kwalifikasies moontlik nie so 'n belangrike kriterium is waarvolgens die preseptore geselekteer word nie (Sien figuur 1).

- Die voorbereiding van die preseptor vir haar rol

Met betrekking tot die voorbereiding van die preseptor vir haar rol in personeelontwikkeling het twintig $(62,5 \%)$ respondente van die preseptorgroep aangedui dat hul geen voorbereiding vir hul rol as 'n preseptor ontvang het nie. Van die twaalf $(37,5 \%)$ preseptore wat

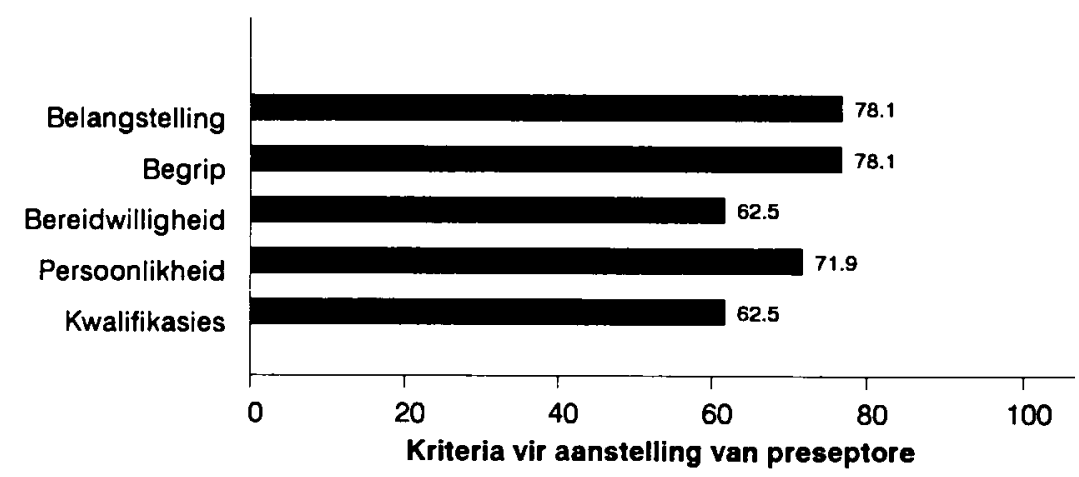

Figuur 1

Preseptore se respons op die redes vir hulle aanstellings 
aangedui het dat hulle voorbereiding ontvang het, het slegs nege aangetoon dat hul deur middel van indiensopleiding vir hul rol voorberei is. Agt van die twaalf preseptore het die metodes van seminare, voortgesette studies, die lees van literatuur en besprekings met die beheerverpleegkundiges aangedui.

- Die preseptor as mees bekwame persoon vir onderrig in die werksituasie

Die redes wat deur $55(38,2 \%)$ van die 144 verpleegkundiges aangevoer word, waarom die preseptor nie as die mees bekwame persoon vir onderrig in die werksituasie ervaar word nie, is ontoereikende

* akademiese kwalifikasies

* kennis van verpleging

* kliniese ervaring

* onderrigervaring

Preseptore met 'n gebrek aan vorige kliniese en onderrigervaring beskik moontlik nie oor die onderrigvaardighede om volwasse indiwidue te onderrig nie.

Doelgerigte beplanning van opvoedkundige geleenthede

- Die behoeftes van verpleegkundiges aan personeelontwikkeling

Die preseptor moet verskillende behoeftes van verpleegkundiges aanspreek in die beplanning van leergeleenthede omrede sommige verpleegkundiges 'n onderbreking van diens gehad het of opleiding onlangs voltooi het. Die bevindinge toon dat 81,25 persent van die preseptorgroep, behoeftes aan personeelontwikkeling by verpleegkundiges identifiseer wat onlangs opleiding voltooi het. Hierteenoor het 25,69 persent van verpleegkundiges wat onlangs opleiding voltooi het, aangetoon dat hul 'n behoefte aan personeelontwikkeling het. Preseptore beskik moontlik nie oor genoeg agtergrondkennis van die verpleegkundige om ten volle die leerbehoeftes van die verpleegkundige te identifiseer nie.

- Voldoende tyd om opvoedkundige geleenthede te beplan

'n Klein persentasie van die preseptorgroep $(15,63 \%)$ teenoor $(53,47 \%)$ verpleegkundiges meen dat hul voldoende tyd tot hul beskikking het om opvoedkundige geleenthede te beplan. Die preseptore in Namibië het nie altyd die tyd om personeelontwikkelingsprogramme te beplan nie, moontlik weens die addisionele verantwoordelikhede om ' $n$ verpleegkundige in beheer van 'n eenheid te wees, bo en behalwe hul onderrigfunksie.

- 'n Beplanningsessie met die verpleegkundige om haar leerbehoeftes te bepaal

Slegs veertien $(43,8 \%)$ van die 32 preseptore teenoor $73(50,7 \%)$ van die 144 verpleegkundiges het aangedui dat die preseptore beplanningsessies met die verpleegkundiges hou om die verpleegkundiges se leerbehoeftes te identifiseer. Laasgenoemde dui op 'n groot leemte in die beplanning van personeelontwikkelingsprogramme. Met betrekking tot die deelname van die verpleegkundige in die beplanning van haar leergeleenthede het 108 $(75,0 \%)$ van die verpleegkundiges aangedui dat hul wel aan sodanige beplanning deelneem. Hierteenoor het $34(23,6 \%)$ verpleegkundiges a angedui dat hul nie altyd die geleentheid kry om hulle bydraes te lewer in die beplanning van hulle eie opvoedkundige leergeleenthede nie.

Die preseptor se onderrigbenadering tydens die implementering van personeelontwikkeling

\section{- Onderrigmetodes}

Uit figuur 2 is dit duidelik dat die preseptore op onderrigmetodes konsentreer wat deel van die saalroetine uitmaak, byvoorbeeld saalrondtes. Die demonstrasies word moontlik aan studentverpleegkundiges aangebied wat die verpleegkundiges dan ook bywoon. Die minderheid preseptore dertien $(40,63 \%)$ teenoor slegs $30(20,83 \%)$ van die verpleegkundiges meen die preseptor gebruik die besluitnemingsessie as onderrigmetode. Met inagneming van die onderrigkwalifikasies van preseptore, bestaan die moontlikheid dat preseptore nie kennis dra van die gebruik van 'n besluitnemingsessie as 'n onderrigmetode nie.

- Tye wanneer personeelontwikkelingsprogramme aangebied word Slegs ses $(18,8 \%)$ van die preseptore teenoor veertien $(9,7 \%)$ van die verpleegkundiges het aangedui dat programme vir nagdienspersoneel aangebied word. 'n Meerderheid, 94 $(65,3 \%)$ van die 144 verpleegkundiges het aangedui dat programme aangebied word wanneer hulle aan diens is, terwyl $35(24,3 \%)$ verpleegkundiges negatief gereageer het. Vyftien $(10,4 \%)$ respondente het geen respons gegee nie. Die moontlikheid bestaan dat verpleegkundiges nie programme bywoon wat tydens hulle aftye aangebied word nie. Dit blyk dat meer as 'n derde van die verpleegkundiges nie die geleentheid het om personeelontwikkelingsprogramme aan diens by te woon nie, wat op'n leemte in die organisasie van leergeleenthede dui.

'n Verdere leemte is geïdentifiseer in 'n item waar die meerderheid preseptore, sewentien $(53,1 \%)$ gemeen het dat die preseptor nie daagliks tyd vir onderrig kan inruim nie.

- Erkenning van die verpleegkundige se reg tot eie oortuigings

'n Positiewe respons is deur 103 $(71,5 \%)$ van verpleegkundiges verkry teenoor $39(27,1 \%)$ verpleegkundiges wat van mening was dat die preseptor nie die verpleegkundige se reg tot eie oortuigings erken nie. Twee $(1,4 \%)$

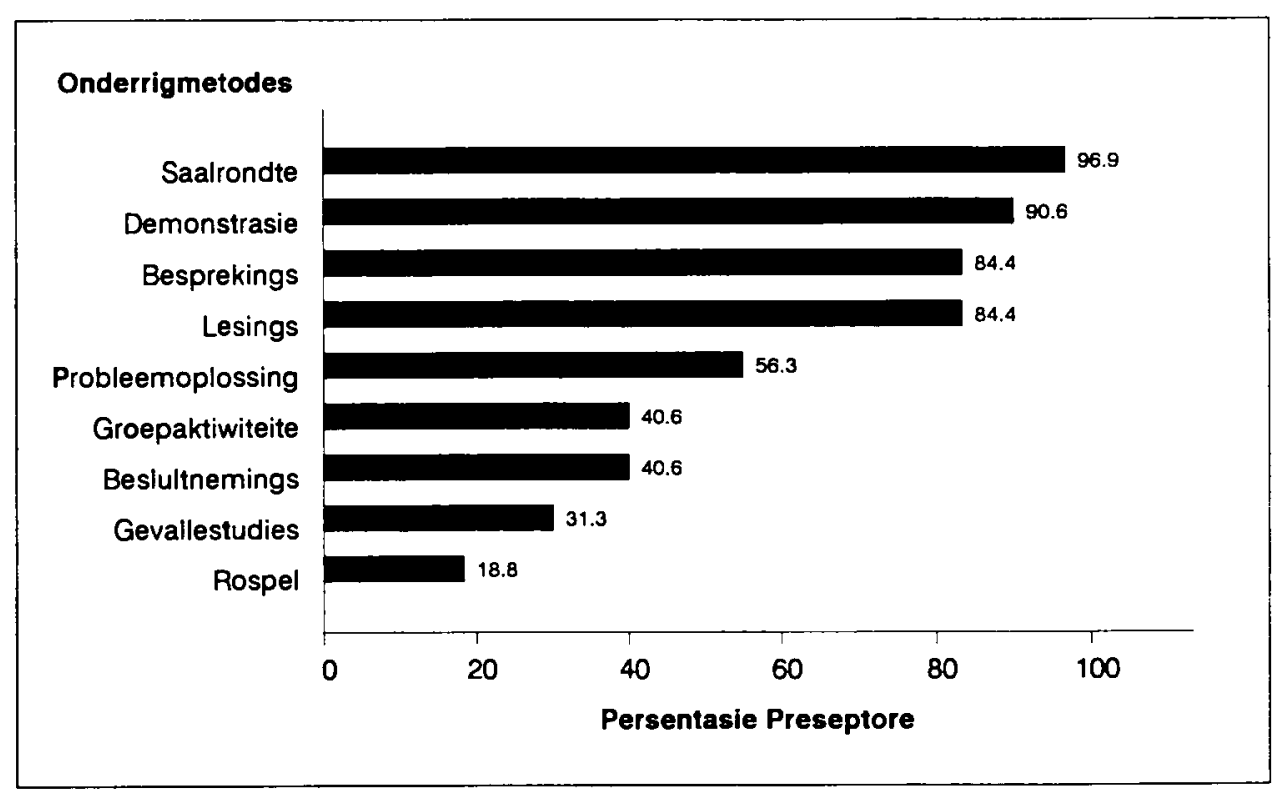

Figuur 2

Die Preseptore se gebruik van onderrigmetodes 
respondente het nie hierdie item beantwoord nie. Uit bevindinge blyk dit dat die preseptore nog tot 'n mate 'n burokratiese houding inslaan en nie die verpleegkundiges se oortuigings erken nie.

Die verpleegkundige en besluit neming

Op die item rakende die preseptor se respek vir die verpleegkundige se individualiteit tydens deelname in besluitneming het $28(19,4 \%)$ van die verpleegkundiges negatief en 114 $(79,2 \%)$ positief gereageer.Die gevolgtrekking is gemaak dat slegs sommige van die preseptore nie ag slaan op die verpleegkundige se voorstelle/insette tydens besluitneming nie.

Die preseptor se evaluering van die verpleegkundige

- Die formele terugvoering van preseptore aan verpleegkundiges

Formele terugvoering het gedui op kommunikasie wat tussen die preseptore en verpleegkundiges moes plaasvind. Die meerderheid van 29 $(90,63 \%)$ preseptore teenoor slegs $67,36 \%$ verpleegkundiges meen dat formele terugvoering oor verpleegkundiges se persoonlike vordering gemaak word. Die preseptor behoort evaluasie as 'n deel van die leerervaring van die verpleegkundige te sien.

- Stel van voorafbepaalde doelwitte Slegs 3,13 persent preseptore teenoor 31,94 persent verpleegkundiges het aangedui dat die preseptor nie verpleegkundiges evalueer aan die hand van voorafbepaalde doelwitte met betrekking tot hulle personeelontwikkeling nie. Ongeveer 32 persent verpleegkundiges weet dus nie watter eindresultate hul tydens evaluasie moet behaal nie.

Slegs $93(64,58 \%)$ verpleegkundiges teenoor $31(96,88 \%)$ preseptore het aangedui dat hulle voor evaluering met voorafbepaalde doelwitte vertroud is.

- Bespreking van die verpleegkundige se vordering

Negatiewe respons is van vyf $(15,63 \%)$ preseptore en $71(49,31 \%)$ verpleegkundiges verkry op die vraag of die preseptor die verpleegkundige se vordering met haar bespreek. Gebrek aan terugvoering kan daartoe lei dat die ondergeskikte nie die geleentheid kry om meer kennis oor haarself te bekom nie.
AANBEVELINGS

- Addisionele preseptore kan preseptorskap nader laat beweeg aan die ideaal van'n een-tot-een grondslag tussen 'n preseptor en 'n ondergeskikte in die eenheid.

- Brink (1989:64) se bevindinge aangaande die internasionale interpretasie van die term preseptor word ondersteun en as aanbeveling

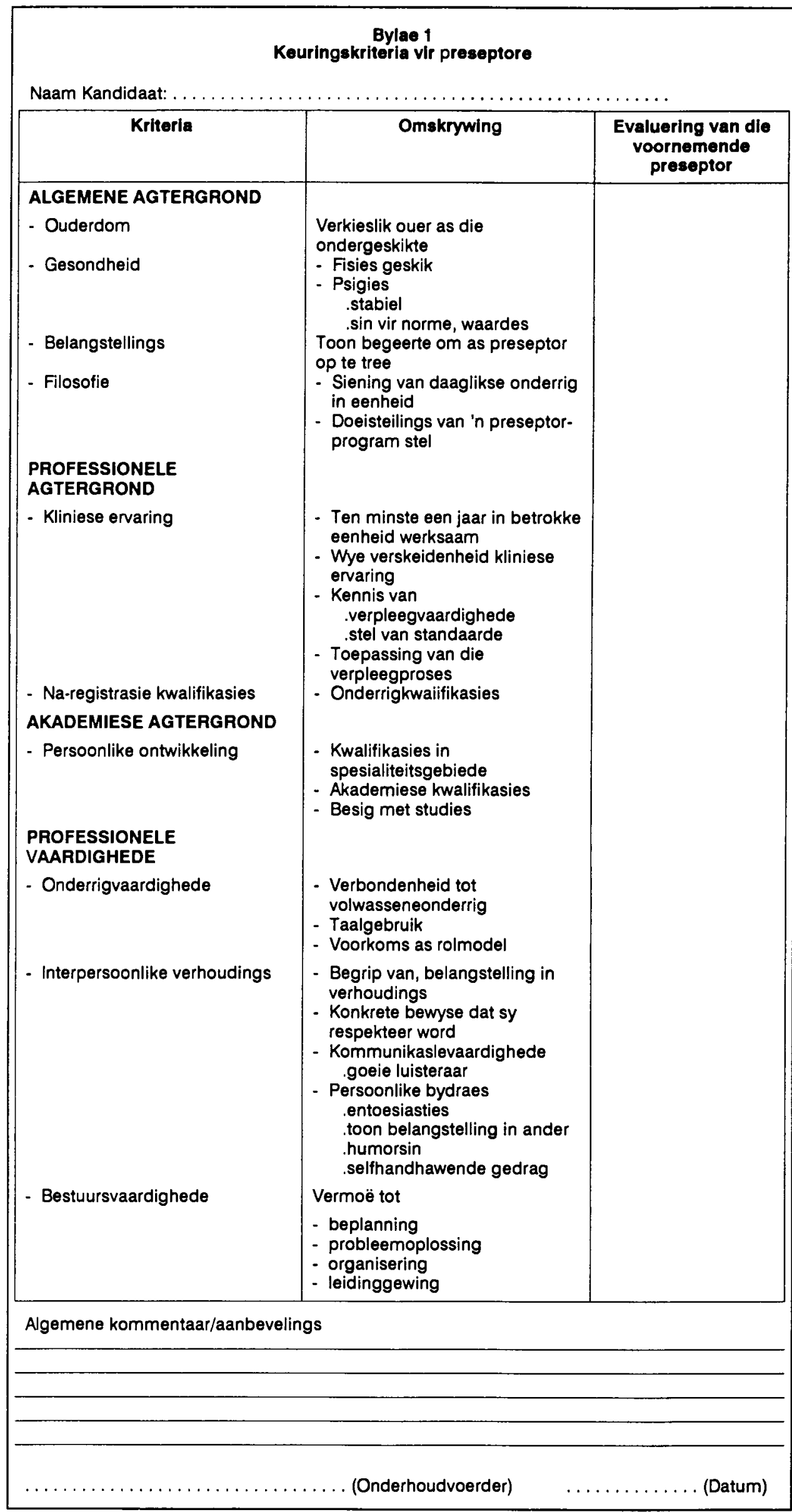


uitgelig:

"The ward sister is the most likely person to function as preceptor but does not automatically become a preceptor on appointment as a ward sister."

- 'n Verpleegkundige in beheer moet eers aan vereiste kriteria voldoen voordat sy spesifiek aan hierdie funksie toegewys kan word. Voorgestelde kriteria is voorts ontwikkel.(Sien bylae 1)

- Die aanbevelings wat voortspruit uit die navorsing kan daartoe bydra dat die preseptore hulle rol meer effektief kan vervul. Die daarstelling van 'n handleiding wat die funksies, verantwoordelikhede en doelstellings van preseptorskap vervat, word as noodsaaklik beskou om preseptore in staat te stel om hulle funksie meer effektief te vervul.

- Daar word aanbeveel dat vraelys 2 (aan die verpleegkundige) volgens behoeftes van die diens, as 'n selfevalueringsinstrument deur die preseptor gebruik word.

- As aanbeveling is 'n voorbereidingswerkgroep vir preseptore ontwerp wat spesifieke probleemareas van:

* beginsels van volwasseneleeronderrig;

* verbale en nie-verbale kommunikasietegnieke;

* probleemoplossing;

* stel van standaarde;

* die rol van die preseptor as veranderingsagent en navorser aanspreek.

\section{SAMEVATTING}

Hoë eise word aan die preseptor gestel om as verpleegkundige in beheer van 'n eenheid haar personeelontwikkelingsfunksie na wense uit te voer. Hierteenoor is dit egter belangrik dat die rol van die preseptor sal voortbestaan om verpleegkundiges in hul praktyk te begelei en professioneel en persoonlik te ondersteun.

\section{BIBLIOGRAFIE}

BACHMAN, D.J. \& RIDLEY, J.M. (1984). Using preceptors for the new
OR nurse. Today's OR Nurse 6 , 7:14-18.

BRINK, H.I.L. (1989). The term preceptor: its interpretation in South African Nursing Colleges and International literature. Curationis 12, 3 \& 4: 62-66.

DAVIS, J.L. (1987). Orientation made easy. Using preceptors and skills checklists. Association of Operation Room Nurses Journal 45, 4: 951, 955, 957, 959 .

DIGBY, P.G.N.(1983). Approximating the tetrachoric correlation coefficient. Biometrics 39 (September):753-757.

DODWELL, M. \& LATHLEAN, J. (1987). An innovative programme for ward sisters. Journal of Advanced Nursing 12, 3: 311-319.

DOUGLASS, L.M. (1984). The effective nurseLeader and manager. 2nd edition. St.Louis: Mosby.

GOLDENBERG, D. (1987/88). Preceptorship: A One-to-one relationship with a triple "p" rating (Preceptor, Preceptee, Patient). Nursing Forum XXIII 1: 10-15.

HART, G. (1988/1989). Teleconferencing: peer support for new graduates and preceptors. The Australian Journal of Advanced Nursing 6, 2: 8-12.

JOOSTE, K. (1991). Die verpleegkundige in beheer van 'n eenheid as preseptor in personeelontwikkeling in opleidingshospitale in Namibië. MA.Cur - verhandeling. Unisa.

MODIC, M.B. \& BOWMAN, C. (1989). Developing a preceptor program: What are the ingredients? Journal of Nursing Staff Development 5, 2:78-83.

MOONEY, V.A., DIVER, B. \& SCHNACKEL, A.A. (1988). Developing a cost-effective clinical preceptorship program. Journal of Nursing Administration 18, 1: 31-36.

MOUTON, J.,MARAIS, H.C., PRINSLOO, K.P.\& RHOODIE, N.J. (1989). Metodologie van die
Geesteswetenskappe: Basiese begrippe. Pretoria: Raad vir Geestelike Navorsing.

MUNRO, B.H.VISINTAINER, M.A. \& PAGE, E.B. (1986). Statistical methods for health care research. Philadelphia: Lippincott.

POLIT, D \& HUNGLER, B. (1987). Nursing Reserach. Principles and Methods. 3rd edition. Philadelphia: Lippincott.

REID, N.G. \& BOORE, J.R.P. (1987). Research methods and statistics in health care. London:Edward Arnold.

SHOGAN, J.O., PRIOR, M.M. \& KOLSKI, B.J. (1985). A preceptor program:Nurses helping nurses. Journal of Continuing Education in Nursing 16, 4: 139-142.

TORNQUIST, E.M.(1986). From proposal to publication. An informal guide to writing about nursing research. Massachusetts: AddisonWesley.

WALTERS, C.R. (1981). Using staff preceptors in a senior experience. Nursing Outlook 29, 4: 245-247.

WALTZ, C. \& BAUSELL, R.B. (1983). Nursing Research: Design, statistics and computer analysis. Philadelphia: Davis.

KARIEN JOOSTE BA CUR (Unisa) BA CUR HONS (Unisa) MA CUR (Unisa) GV GW GGV GD GA Departement Verpleegkunde Unisa.

CORNELIA M. NEL D Litt et Phil (Unisa) Departement Verpleegkunde Unisa 